
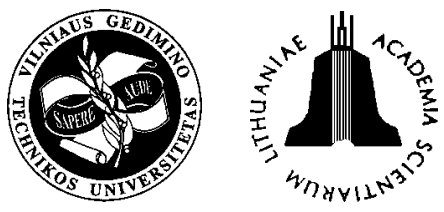

ISSN 1648-4142 TRANSPORT

TRANSPORT - 2004, Vol XIX, No 2, 75-81

\title{
SOME ELEMENTS OF THE RO-RO TERMINALS
}

\author{
Ričardas Maksimavičius \\ Klaipèda University (KU), Bijūnu g. 17, LT-5800 Klaipèda, Lithuania \\ E-mail:laivyba@jtf.ku.lt
}

Received 2004-01-07; accepted 2004-02-17

\begin{abstract}
Although sea freight accounts for the major part in ro-ro freight transportation schedule, due and timely processing of cargo and preparation for shipment are to a particular extent affecting the ro-ro freight duration. It is therefore essential to minimize the freight processing time at the ro-ro terminal. Otherwise ship schedule might be interfered and even the operation of a terminal itself and port traffic is affected.

Another problem to be encountered quite often is that ro-ro terminal is not in the position to physically accept and process the arriving freight. This is mainly pre-conditioned by an insufficient number of terminal gateways, the shortage of customs and border control units, and inadequate parking/storage capacity and arrangement at the terminal.

The presented paper provides a solution to the said problem by giving due emphasis to the proper calculation of the capacities of terminal gateways, customs and border control facilities. Thus an attempt is made to optimize the terminal operation efficiency and attractiveness and reduce the factors impairing ro-ro freight transportation, particularly in respect of transportation time.
\end{abstract}

Keywords: terminal gateways, customs and border control facilities, ro-ro, parking/storage capacity.

\section{Introduction}

Present day Lithuanian ro-ro liner service operators are encountering a drastic competition in ro-ro shipping market and strive to retain their positions as well as break into and establish themselves in new ro-ro shipping markets. It is worthwhile to mention, however, that close cooperation between other transport branches and ro-ro terminals is not always feasible, which in turn would encourage the negative factors impacting freight transportation, and thus hinder the complex assessment thereof, and also affect the attractiveness of such transport, and, consequently, traffic flows of such freight. Even more problems arise when they fail to establish an adequate cooperation and interaction level between the port terminals and ro-ro liner operators.

Ro-ro freight transportation makes possible communication without restrictions for road vehicles to travel by sea (when no other communication means is possible, or is very expensive); but along with existing 'parallel' road network routes, it offers alternative sea transportation which allows to deliver freight at both cost- and timeefficient terms.

Many of new ro-ro freight lines are forced to quit operation and close down quite soon after emerging on the market, as having no prospects, all due to numerous reasons like failed performance and failed attempts to attract enough freight, underestimated advantages, short- comings and threats, and exaggerated possibility evaluation, misevaluated intensity of freight flows and much too optimistic outlooks, inadequate interpretation or underestimation of factors that produce negative effect on ro-ro freight transportation, etc.

This study aims to effect the minimization of freight processing time on ro-ro ferries, by ensuring the required number of terminal gateways, customs and border control, and parking/storage facilities.

Over the last decade relatively few research papers have been filed to focus on ro-ro shipping issues. Important research carried out in the area of transport engineering, economics and logistics has been of great influence on the ro-ro shipping developments. Some of the studies feature kind of descriptive narration, while others offer strategic solutions for ro-ro shipping development. Over the last years discussions have been held on feasible 'pushing' of road vehicles on to the sea, railway and inland waterway transport, what has stirred up noticeable attempts of scientists and researchers to realize those ideas. Marco Polo Project has also contributed into the matter to a large extent.

The research made by foreign and Lithuanian scholars into ro-ro and short sea shipping can be broken down according to the areas of study: cargo flow analysis; feasibility of freight transfer to ro-ro liner shipping and short sea liner shipping; analysis of the existing and future fleet in view of ensuring better client services; improvement 
of technical parameters of the fleet and advanced technical development of the fleet; port development and use for ro-ro shipping and port development; advanced organizing structures influencing ro-ro freight transportation; multimodality and advantages of multimodal freight transportation; IT application and search for new solutions to improve ports and shipping lines services; logistics and its importance; law, legislation and their improvement.

A thorough outline of the technical issues in ro-ro shipping business has been given [1,2], to help maintain a deeper insight into the technological procedures of roro ships and to some extent in terminals, feasibility outlook on shipping, transport and terminal development [3-5], passenger shipping [7, 8].

Studies of the main and additional Lithuanian and foreign research sources have revealed the issue as top urgent, thus leading to a possibility to resolve the pending topical matters.

\section{Analysis of ro-ro freight transportation on the Baltic}

Currently on the Baltic trading frame small and medium-sized ro-ro ships, i.e. ships that account for loading road length up to 1800 metres are predominant. This can be explained by the fact that ro-ro liner operators in order to ensure greater frequency of transport services normally run several liners of smaller capacity. Smaller ships usually operate in ro-ro liner service where a single voyage does not exceed $14 \mathrm{hrs}$. Whereas on longer voyages, they employ medium-size vessels and the routes to exceed $24 \mathrm{hrs}$ are mainly serviced by medium and large roro ships (where loading road capacity exceeds 1800 metres).

Specialized ro-ro vessels (interlinked to terminals by liner service) on the Baltic account for relatively minor part, up to 20 percent. As the shipping companies prefer to operate more multi-purpose ships which allow to be independent from linear shipping and terminals they are servicing. The specialized ro-ro ships include ro-ro railway ferries, since both the terminal is bound to the ship as the ship is bound to the terminal, this being caused by complex loading facilities operated in ro-ro railway ferry terminal that are incompatible to other port facilities. The price of such ships and ro-ro terminals is by far bigger than that of a conventional ro-ro terminal which is not involved in railway carriage loading, and most often such terminals can not be adjusted to operate other types of ships, meanwhile modernization and conversion of vessels involve major investments. However, the processing efficiency of such a specialized type of ships in ro-ro terminals is higher than that of multi-purpose ships. As an example we can mention simultaneous loading on two cargo decks.

Besides their main involvement ro-ro ships carry

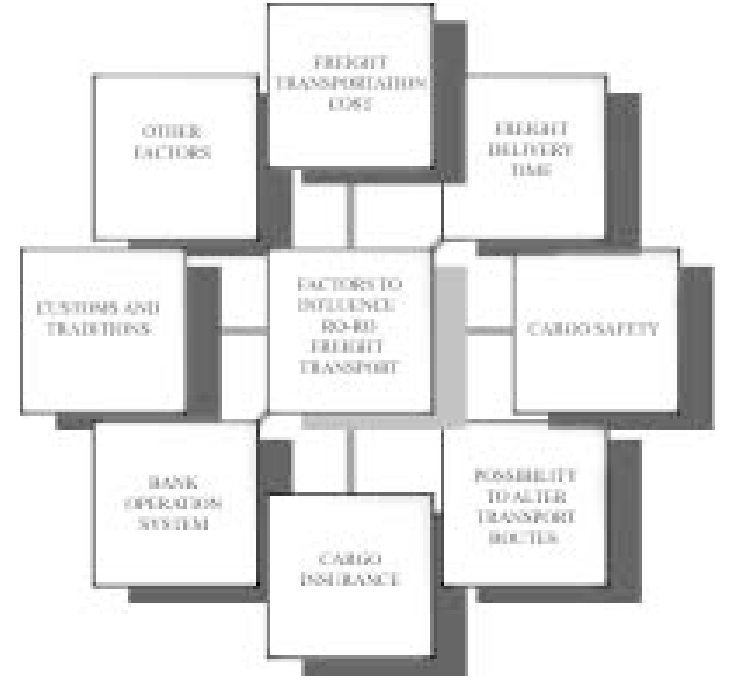

Fig 1. Factors influencing ro-ro freight transportation

passengers what also accounts for considerable share of profit. Yet it must be mentioned that such ships often are subject to certain restrictions especially when hazardous cargoes are concerned.

The majority of ports, while realizing the advantages of ro-ro liner transport (as ro-ro services ensure a continuous flow of ships and cargoes) are concerned to construct own ro-ro terminals or adjust the existing ones for ro-ro transportation. Some ports feature this as an additional business, whereas other ports are specializing in ro-ro as major activity. Normally ro-ro terminals are concentrated in sites with good access to road and railway infrastructure. The availability of ro-ro terminals of a close contact with major transport mains and units considerably increases the advantage and competitiveness of such terminals.

It is therefore necessary to emphasize that attempts of ro-ro services (ships, lines and terminals) operators alone to interconnect the ports by ro-ro liner transport cannot ensure the continuous traffic and flow of such transport. For this, multiple various objective and subjective factors have to be considered.

Taking into consideration the objective and subjective factors (Fig 1) to likely influence ro-ro freight transportation, we can minimize them, since any of them affects the transport in its own way. Some factors like roro transport cost, time and safety can be influenced, i.e. reduce and minimize their effect on ro-ro transport. When other factors can be dealt with at a certain period of time by gaining experience in ro-ro services, other factors like weather calamities fall out of human control nor influence. These have to be taken into consideration and assessed while effecting and developing ro-ro transport frame.

Cargo transport cost largely affects the decision of cargo carriers when choosing the transport means, how- 
ever, cargo transport cost alone without consideration of cargo delivery and processing rates/terms, safety etc. would be mistaken (inappropriate) and should thus be taken into account.

Irrespective of that the major part of time scheme in ro-ro transportation accounts for freight transportation we have to assume that total transportation time shall be influenced by the arrangement of operations at ro-ro terminals in both private companies and state institutions operating there.

Taking a look at the scheme of cargo transportation by ro-ro ships (Fig 2), we can see that a Cargo Transport Unit (CTU) prior to embarkation, from ticket booking, has to complete numerous formalities at the ro-ro terminal, starting with entering the terminal, customs procedures and ending up at the storage site awaiting embarkation and boarding the ship.

Most of the terminals observe a steady wrong convention that control formalities cannot largely influence the freight transportation time, as the ro-ro transport by sea accounts for the major part in the transportation itself.

Statistically, it has been proven that max freight (ca $80 \%$ ) is delivered by CTU at the ro-ro terminal gateway 2 to 3 hrs prior ship departure, and some $5 \%$ of freight arrives less than 1 hour before the departure. It is during this last hour that terminal services (border control, customs, ship port agency etc) receive maximum workload, and given the insufficient gateway inlet capacity, vehicle lines form. Concurrently queues line up at the customs and border control (due to the insufficient number of such facilities), which further mount to hinder both CTU processing for boarding the ship and embarkation itself. All of them affect total embarkation time, as without border control and customs clearance no CTU is allowed to board the ship. In such case two options are possible - either the ship is to be delayed until CTU can embark; or a CTU is left at the terminal, as any delayed departure of ro-ro liner against

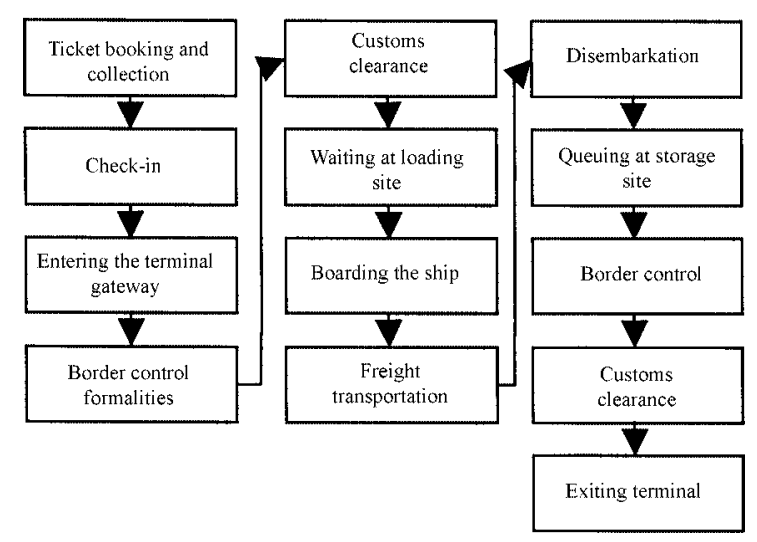

Fig 2. Freight transportation by ro-ro ships the schedule may have a bad impact on other ships traffic, not only on ro-ro liners but also tramp ships etc. and port traffic control operation. Mostly linear shipping is given the first priority at port, which in that case would hinder smooth operation in the port and affect traffic planning inside the port.

It is therefore necessary to provide at least a minimum number of CTU port gateways along with the customs and border control units to ensure a due complex service of ro-ro liner during embarkation.

Important as such is also a matter of storage site (platform) capacity and location at the terminal, as the majority of CTU arrives before ship departure. A certain part of CTU comes earlier and following customs and border clearance has to be placed in the terminal storage (parking) site. Besides, on ship arrival at berth, it takes a certain period of time to discharge the ship, meanwhile CTUs waiting for the embarkation have to be parked in safe area. As to the CTUs disembarking from ro-ro ship, it is not always that they leave the terminal immediately, and thus need accommodating storage space.

\section{Calculations of the capacity of ro-ro terminal gate- ways, customs and border control, and ctu storage facili- ties}

The number of ro-ro terminal gateways is an important index to ensure the terminal operations efficiency and ships processing rates. As insufficient number of gateways may cause traffic congestions at the terminal gateway and would meanwhile keep the control units idle which in its turn will affect the loading rate.

General intensity of CTU processing at the gateway can be calculated as follows:

$$
\mu=\frac{G}{t_{a p t}},
$$

where $G$-number of gateways in a terminal; $t_{a p t}-$ single CTU processing time, min.

We may consider a single-channel or multi-channel terminal gateway system. An example of single-channel gateway system is the existing International Ferry Terminal (IFT) in Klaipeda.

Arriving CTUs at the terminal gateway are arranged according to Poison's law when intensity $\lambda$. CTU processing time is set according to exponential law. On condition that under normal gateway operation the gateway workload $\varphi$ should not exceed 1 .

$$
\varphi=\frac{\lambda}{\mu}<1 .
$$

Then minimum gateway number $B_{\text {min }}$ for estimated CTU flow has to be as follows: 


$$
G_{\min }=\lambda \cdot t_{\text {apt }} .
$$

Otherwise the reliability is incomplete, not all necessary number of CTUs can be accepted.

Thus average queuing time outside the terminal gateway shall be:

$$
W_{e}=\frac{\varphi}{(1-\varphi) \mu} \text {. }
$$

Mean gateway entrance time per CTU shall be:

$$
W=W_{e}+t_{a p t}=\frac{\varphi}{(1-\varphi) \mu}+t_{a p t}=\frac{\lambda t_{a p t}^{2}}{B\left(B-\lambda t_{a p t}\right)}+t_{a p t} .
$$

On condition $W \leq T$, where $T$ is relative time, as an example may be taken CTU check-in and completion of loading, therefore:

$$
B^{2}-\lambda t_{a p t} B-\frac{\lambda t_{a p t}^{2}}{T-t_{a p t}} \geq 0
$$

As the required necessary number of terminal gateways a minimum whole positive number of this inequality can be accepted .

Average number of CTU awaiting outside the terminal gateway is:

$$
P_{q}=\frac{\varphi}{1-\varphi} .
$$

Average number of CTU lined up per single gateway shall be:

$$
L_{q}=\frac{P_{q}}{B}=\frac{\varphi}{(1-\varphi) B} .
$$

Thus passages to a gateway and export platforms on the terminal have to be designed based on the average number of CTU waiting outside terminal gateway $P_{q}$ and average number of CTU lined up at a single gateway $L_{q}$ values.

Under normal conditions cargo flows on ro-ro liner shipping and steady and slightly shifting are known, it is fairly easy to calculate the required terminal gateway quantity, mainly considering average CTU awaiting outside the gateway, since this will determine the loading rate, in other words, the less gateway available, the bigger CTU queues line up at the terminal.

For port terminals the number of available customs units is important. The amount of such units available will pre-determine CTU lines into the customs and border control units.

Research has shown the maximum customs and border control workload during rush hours, i.e. 2-3 hrs before departure. At this time the number of CTU to undergo clearance will reach the intensity as folllows:

$$
\lambda=\frac{I_{p}}{\Delta t_{p}}
$$

here: $I_{p}$-number of departing CTU; $\Delta t_{p}$-time interval for maximum number of CTU to be cleared.

We set up a statistical clearing time at customs and border control unit for a single CTU $t_{i}$. Thus average clearing time for single CTU at customs and border control unit shall be:

$$
t_{a}=\frac{\sum_{i=1}^{K} I_{i} \cdot t_{i}}{\sum_{i=1}^{K} I_{i}}
$$

where: $I_{i}$ - number of customs clearings in period of time $\Delta t ; t_{i}$-clearance time mean; $K$ - number of customs clearings.

Thus average clearing time for a CTU at customs unit shall be:

$$
W=W_{q}+t_{a},
$$

where: $W_{q}$ - average time of queuing for clearance per single CTU.

Dependent on CTU loading mode and cargo nature, as well as customs facilities, clearing time can last from 5 till 30 minutes. Statistically, for instance, at the Klaipeda port it takes up to 15 minutes to clear one CTU, similar clearing rate in Germany.

Customs units in terminals are expected to serve as single-channel complex processing facility at the processing intensity rate $\lambda$, the processing time can be arranged by an exponential law at the following intensity:

$$
\mu=\frac{l}{t_{a}}
$$

where: $l$ - number of customs units in a terminal.

In this case average clearing time for a single CTU will account like this:

$$
W=\frac{\lambda t_{a}^{2}}{l\left(l-\lambda t_{a}\right)}+t_{a} .
$$

Under condition $W \leq T$, we have:

$$
l^{2}-\lambda t_{a} l-\frac{\lambda t_{a}^{2}}{T-t_{a}} \geq 0
$$

In this case the required number of customs units in terminal shall be:

$$
l \geq \frac{\lambda t_{a}\left(1+\sqrt{\frac{l+4}{T-t_{a}}}\right)}{2} .
$$


Average number of CTU to undergo customs clearance per single customs unit shall be:

$$
L_{q}=\frac{\varphi}{(1-\varphi) l}-\varphi^{2}
$$

Therefore in order to obtain the number of customs units, it is necessary to calculate average number of CTU awaiting at a single customs unit $L_{q}$.

If a wrong value of customs and border control units is found, the efficient clearance of all CTUs arriving at the terminal in rush hours, will fail. This might result in possible ship delay and breach of the schedule, especially when a next docking is imminent at the same berth right upon departure of current ship.

Number of CTU $S_{s(\max )}$, to use the accommodating storage site shall depend on:

- $\quad$ Ship arrival at the terminal time $t_{i}$;

- Number of CTU disembarking every ship docked $i$;

- Average storage (parking) time at a terminal site, $t_{s}$;

- $\quad$ Part of CTU to use the parking site at the terminal, $i_{s}$.

So we can calculate the number of CTU to use the terminal parking/storage sites as follows:

$$
S_{s(\max )}=\sum_{j} i_{s} i_{j}
$$

Here we sum up based on all $j$, which $t_{i}-t_{s}<t_{j}<t_{i}$.

For initial values $S_{s(\max )}$ we take a maximum $S_{s_{i}}$, which we set up by evaluating within a period of time from $t_{1}$ to $t_{n}+t_{s}$, where $n$ means number of ships calling in.

Therefore:

$$
S_{s(\max )}=\max _{1 \leq i \leq n}\left\{S_{s_{i}}\right\} \text {. }
$$

The parking/storage sites on ro-ro terminals are arranged separately for the arriving and for the departing CTU, or certain designated parts of the sites are used instead. Considering the arrangement of parking grounds, we should make sure that accommodating (parking) sites for departing CTU are located conveniently close to the embarkation area so that to reduce time consumption during loading operation, whereas the sites for the departing CTU may be at some distance. Taking into account that any freight consignee/shipper (trailer) requires a separate parking lot, we also have to assume that a specific sized freight may require several storage lots, then:

$$
n_{a k}=S_{s(\max )}\left(1+P\left\{n_{r}>m_{r}\right\}\right),
$$

here: $P\left\{n_{r}>m_{r}\right\}=\beta_{r}-$ part of special-sized freight.
Then we have average value for several CTU:

$$
n_{r}=\frac{\sum \gamma_{r}}{\sum S_{i}}
$$

here: $\gamma_{r}$ - number of parking lots for CTU; $S_{i}$ - number of CTU to use the parking lots.

The number of parking lots is of importance to both a CTU awaiting embarkation and CTU after disembarkation, since some of the departing CTU enter the terminal gateway, pass the customs and border clearance well before the ship arrival, thus we need a certain capacity of accumulating storage facilities in ro-ro terminal what will accordingly facilitate the customs and border control unit operation on ship embarkation and departure.

CTU disembarking from ship also require accommodating storage lots, since all CTU are not in the position to complete customs clearance and exit the terminal. For this reason in order to avoid massive CTU congestions at customs points, the excessive CTU have to be placed in accommodating storage sites which capacity will depend on customs operation and quantity of disembarking CTU. Insufficient storage facilities may hinder the disembarkation as the CTU to be discharged will have to stay aboard the ship because of the absence of storage facilities for disembarking CTU. This has happened in Mukran where due to the reduced cargo flows, they decreased the number of customs points, however a sudden boost of freight followed, yet the number of customs points remained unchanged and accommodating storage facilities have not increased, what mounted up to hinder the ship discharge.

\section{Practical calculations of terminal gateways, customs and border points and storage facilities}

For the below practical calculations the above methodology has been applied.

As an example we have calculated the number of gateways, customs and border point facilities required for an intended ro-ro freight flow.

The calculations showed (Fig 3) that the number of terminal gateways has to be planned based on the average number of CTU awaiting outside terminal gateway $P_{q}$ and average number of CTU queuing at the single gateway $L_{q}$. Thus, we may achieve the optimal use of gateways, and no CTU lines outside the gateways will form what will have a positive effect to ro-ro freight processing before accessing the terminal.

Therefore the increased number of terminal gateways may result in the reduced number of CTU at the terminal gateway as well as CTU lines outside terminal gate. It is proved that in order to optimize the terminal efficiency whilst the increased freight flows, the terminal gateway throughput must be increased. 


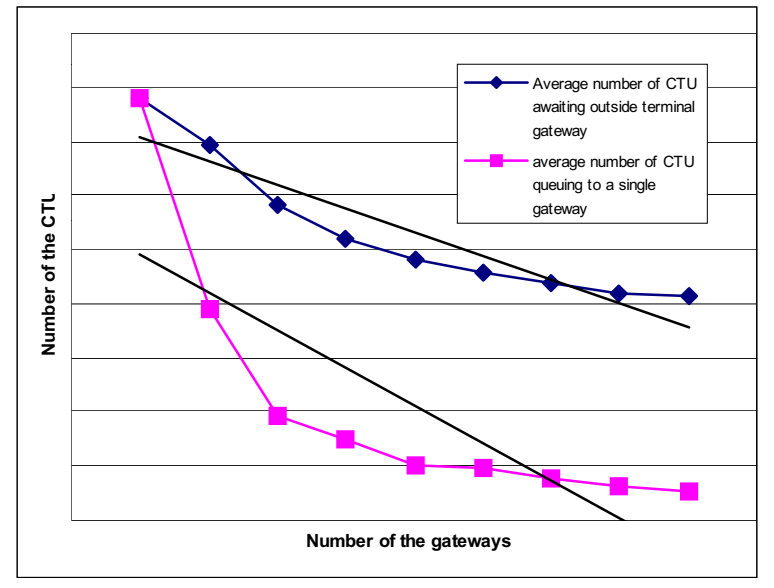

Fig 3. Average number of CTU awaiting outside the terminal gateway and average number of CTU queuing to a single gateway

However, even the optimum number of terminal gateways is unable to resolve the issues within terminals when customs and border control performance is concerned, as the terminal cannot accept more CTU than customs units can process, so again we point out that both extra customs and border control facilities are necessary.

Consequently we have to paralelly establish a respective number of customs points dependent on the roro freight flows and the number of terminal gateways available (Fig 4). So to say with the increased gateway throughput, and accordingly larger number of CTU to pass customs clearance we can see in Fig. 4 that customs facilities have to be duly extended, too. Otherwise the increase of gateway throughput has no sense as such.

Having adjusted the quantities of gateways, customs and border control facilities, we have to evaluate the areas where CTU can be stored following the completion of customs and border procedures. To avoid the CTU congestion at the control points, the excessive CTU has to be located within accommodating storages (Fig 5), the capacity of which depends on customs operation and the number of arriving CTU. The shortage of storage can hinder discharge operation due to delay of CTU onboard the ship, simply because there is no space where to place CTU.

As mentioned above, along with the increased number of gateways, customs and border facilities, CTU storage grounds capacity has to be increased. Otherwise, when a larger number of CTU than that designed for actual storage space is accepted at the terminal, it might simply form congestion at the customs clearance points and within, and may also cause the freight delays outside terminal, because the terminal will have no capacity to accommodate such rows of CTU.

A similar situation has been currently observed at the IFT what actually requires urgent decision to be made,

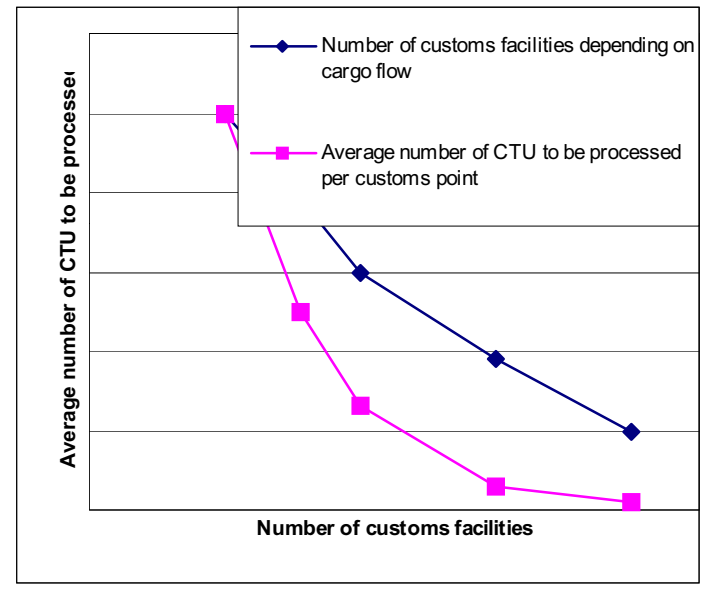

Fig 4. Number of customs facilities and average number of CTU to be processed per customs point

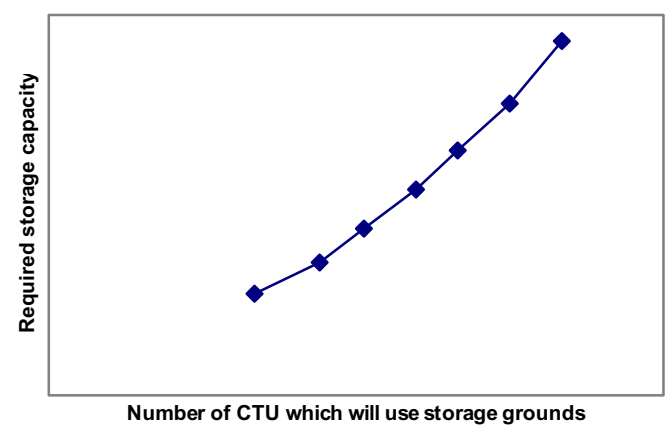

Fig 5. The required storage capacity depending on the number of CTU

since the available terminal facilities fail to accept and process the existing cargo flows. This often appears as the cause of ro-ro ship processing hindrances mostly we could specify the belated arrival at the terminal arrangement of departure formalities which usually result in ship delay. This could be explained by the shortage of gateway throughput (single gateway pass point is operating), and inadequate customs/border control facilities. Yet this is not the solution to the problem, even though if we rectify the issues as mentioned before, we cannot resolve the whole problem in principle, because there is a shortage of accommodating storage space in the terminal IFT. To conclude, the situation demands a complex approach in order to improve things. However the prevailing attitude exercised by the terminal authority that believes once a terminal is not in the position to handle the matter, the ro-ro ship laydays at port are to be prolonged, which is a fallacy and does not encourage the real decision-making to improve terminal operation, by shifting all the issues toward the ro-ro liner operator. To put it clearly, the terminal is not concerned about the optimization of its performance, yet simply forcing the shipping line operators extend ships laydays and embarkation time. 


\section{Conclusions}

Whilst developing the ro-ro liner shipping and freight transportation, numerous factors have to be considered so that to enable possible minimization thereof, particularly when it comes to issues of freight processing and preparation for ro-ro transportation.

1. To enhance and optimize ro-ro ship processing, close cooperation and interaction between terminal and shipping line is mandatory.

2. To ensure proper terminal operation and efficient ship processing a certain number of CTU ready for embarkation must be available what might be achieved by due increase of terminal gateway throughput, customs and border control facilities.

3 . Yet the increased number of gateways (throughput), customs and border facilities alone, cannot always resolve the issue of timely and due freight processing, as long as the terminal accommodating storage facilities remain insufficient and misarranged.

4. All terminal facilities like gateways, customs and border control and accommodating storage sites and their arrangement have to be duly adjusted and coordinated.

5. Application of Marco Polo Project should serve as an incentive for ro-ro terminals to optimize the terminal operation, efficiency and development, using the EU assistance.

\section{References}

1. Gray M. Ro-ro ships and shipping. Fairplay publications, 1985. $174 \mathrm{p}$.

2. Mangan J., Lalwani C. Modelling Port, Ferry Choice in RoRo Freight Transportation. International Journal of Transport Management, London. Elsevier Science, 2000, No 1, p. $15-28$.

3. Paulauskas V. Optimal Ship Selection Principles in Linear Shipping. Transport Engineering (Transportas), 2000, Vol XV, No 2, p. 53-59 (in Lithuanian).

4. Baublys A., Petrauskas B. Transport terminals (Transporto terminalai). Vilnius: Technika, 2002. 285 p. (in Lithuanian).

5. Paulauskas V. Port Development. Kaipeda University Publisher House, 2000. 284 p. (in Lithuanian).

6. Lo H. K. A Cell-Based Traffic Control Formulation: Strategies and Benefits of Dynamic Timing Plans. Transportation Science, Vol 35, No 2, May 2001, p. 148-164.

7. Butkevicius J. Modelling of the Dependence of Travel Frequency on the Length and Duration of a Journey, Improvement of City Passenger Transport Systems. Transport, 2002, Vol XVII, No 6, p. 223-225.

8. Butkevicius J. Passenger transportation (Keleivių vežimai). The monograph. Vilnius: Technika, 2002. 414 p. (in Lithuanian). 